\title{
Análisis temporal de la cobertura en sabanas antrópicas de Sucre, Colombia
}

\author{
Temporary analysis of the covering in antropic savannas of Sucre, Colombia
}

De La Ossa-Lacayo, Alejandro1* M.Sc, Ballut-Dajud, Gastón² M.Sc, Monroy-Pineda, María C² M.Sc.

${ }^{1}$ Universidad de Sucre, Grupo de Investigación en Biodiversidad Tropical, Selvagua S.A.S. Colombia.

${ }^{2}$ Universidad de Sucre, Facultad de Ingeniería, Programa de Ingeniería Civil, Colombia.

\section{Key words:}

Anthropic savannas; coverage analysis;

Sucre;

Colombia.

\begin{abstract}
The present work determines by satellites images interpretation the behavior of the covering of the anthropic savannas of Sucre, Colombia, from 1985 at 2017 emphasizing in its current state. In accordance with their structure the secondary savannas assemble: semi anthropic savannas, anthropic savannas, artificial wooded savannas and artificial without trees savannas. The results show in accordance with the percentage changes in function of the evaluated periods that the artificial wooded or without trees savannas increased their areas, what would imply a slow sucesional and persistent degradation of the whole system. It points out that the biggest negative cause is generally represented by the intensive cattle grazing and the adaptation of pasture through the persistent and successive deforestation and burns. Conclude that the system of anthropic savannas presents a slow degradation and that a loss of original biotopes exists.
\end{abstract}

Palabras Clave:

Sabanas antrópicas; análisis de cobertura; Sucre;

Colombia.
INFORMACIÓN

Recibido: 07-10-2016;

Aceptado: 22-03-2017.

Correspondencia autor:

alejandrodelaossa@yahoo.com

\section{Resumen}

El presente trabajo determina mediante interpretación de imágenes satelitales el comportamiento de la cobertura de las sabanas antrópicas de Sucre, Colombia, desde 1985 a 2017, enfatizando en su estado actual. De acuerdo con su estructura agrupa a las sabanas secundarias como sabanas semiantrópicas, sabanas antrópicas, sabanas artificiales con arbolado y sabanas artificiales sin arbolado. Muestran los resultados que de acuerdo con los cambios porcentuales en función de los periodos evaluados, se puede indicar que las sabanas artificiales con o sin arbolado aumentaron sus áreas, lo que implicaría una degradación sucesional lenta pero persistente de todo el sistema; señala así mismo que la mayor causa negativa está representada generalmente por el pastoreo intensivo y la adecuación de potreros a través de la constante y sucesiva deforestación y quema. Se puede concluir que el sistema de sabanas antrópicas presenta una degradación lenta y que existe una pérdida de biotopos originales. 


\section{INTRODUCCIÓN}

El departamento de Sucre, se subdivide en cinco subregiones fisiográficas: Golfo de Morrosquillo, Montes de María, Sabanas, San Jorge y La Mojana; la subregión sabanas, está situada en la parte central de departamento, se inicia a partir del declive de los Montes de María hasta inicios de la depresión del bajo Cauca y San Jorge, ocupa $2.101 \mathrm{Km}^{2}$, que representan el $20,7 \%$ del total de la extensión departamental (AGUILERA-DÍAZ, 2005).

Indica AGUILERA-DÍAZ (2005) que la transformación del bosque seco tropical y del bosque muy seco tropical en lo que hoy es conocido como sabanas, en el departamento de Sucre se inició hacia el siglo XVI y alcanzó su máxima expresión en el siglo XVIII. Para tal fin, se usó la tala y la quema posterior; la tala se hacía a mediados de la época seca y la quema un poco antes del inicio de la época de lluvias, para que cuando empezara el ciclo de precipitaciones se favoreciera el establecimiento de pasturas y con esto la llegada del ganado desde la depresión del Bajo San Jorge y el Bajo Cauca. Este sistema de trashumancia todavía perdura en el manejo de la ganadería extensiva de la economía regional (DE LA OSSA y BOTERO, 2013); y es la causa de la transformación del paisaje natural de lo que hoy se conoce como sabanas del departamento de Sucre en la costa Caribe de Colombia (DE LA OSSA-LACAYO et al., 2016).

De acuerdo con lo propuesto por RORHIDI y HERRERA (1977) y asumido por DE LA OSSA-LACAYO et al. (2016), las sabanas antrópicas o secundarias, teniendo en cuenta su extensión y la intensidad de la influencia humana, pueden ser diferenciadas en: sabanas semiantrópicas, formadas en general por la flora herbácea original del biótopo y de su alrededor, bajo una influencia antrópica no muy intensa y que no se repite regularmente. En éstas sabanas, la flora es propia del ecotopo original, pero el ecosistema es ajeno a él; sabanas antrópicas, se desarrollan bajo una influencia profunda continua o regularmente repetida de tala, quemas constantes y pastoreo intensivo; ni la flora ni el ecosistema son propios del ecotopo, aunque ambos tienen continuidad sucesional; y sabanas artificiales, formadas por la actividad humana después de la destrucción completa de la vegetación original y de las sabanas antrópicas. En este caso, la flora y el ecosistema son igualmente ajenos al ecotopo y no tienen continuidad sucesional con la flora del ecosistema original y existe la predominancia de pastos introducidos.

Cerca de $50 \%$ de los suelos del departamento de Sucre son de uso ganadero y sin duda, obedecen a transformaciones llevadas a cabo desde el Siglo
XVI, momento desde el cual se inició la sabanización del bioma tropical alternohígrico predominante en esta región (DE LA OSSA-LACAYO et al., 2016). La ganadería bovina se caracteriza por ser de tipo extensivo, escasa preparación tecnológica, bajo nivel empresarial y de baja productividad (VILORIA, 2005; AGUILERA-DÍAZ (2005).

Mediante la interpretación de imágenes satelitales, en el presente trabajo se hace un análisis temporal de la cobertura vegetal de la denominada subregión sabanas de Sucre, entre los años 1985 - 2017, que incluye globalmente los municipios de San Pedro, Los Palmitos, San Juan de Betulia, Sincé, Galeras, Sampués, El Roble y Corozal, con cubrimiento de un área equivalente a 202.717,2 ha. Se describen los diferentes tipos de sabanas antrópicas y se evalúa su cambio en extensión en función del tiempo.

\section{MATERIALES Y MÉTODOS}

Zona de estudio: Situada en la parte central de departamento de Sucre, se inicia a partir del declive de los Montes de María hasta inicios de la depresión del bajo Cauca y San Jorge, constituida por los municipios de Sincé, El Roble, San Pedro, Sampués, Los Palmitos, Galeras, Buenavista, Corozal y San Juan de Betulia, los cuales tienen un área de 2.101 $\mathrm{km}^{2}$, que corresponden a $20,7 \%$ del total del territorio departamental. Esta región está conformada por numerosas sierras y colinas formando ondulaciones que van desde los 70 hasta $185 \mathrm{~m}$ de altitud (DANE, 2005).

El clima es característico de las zonas de bosque seco tropical, persisten relictos de vegetación secundaria; se dan rastrojos y extensas áreas de pastizales. Se le conoce como sabanas antrópicas por las fuertes intervención humana en este sistema ambiental, con predominio de paisaje de lomerío. La temperatura promedio anual es de $27,2^{\circ} \mathrm{C}$, la precipitación fluctúa entre 990 y $1.275 \mathrm{~mm}$ anuales y la humedad relativa del $80 \%$. Es la subregión que padece con mayor rigor la estación seca, lo que conduce a la trashumancia o traslado del ganado vacuno y equino a las subregiones de La Mojana y San Jorge (DE LA OSSA y BOTERO, 2013).

Métodos: Para el estudio de las coberturas y su evolución temporal (SALINERO, 2008), se utilizó la colección de imágenes del satélite Landsat (CARDOSO et al., 2014) entre estos 4-5 TM, 4-5 MSS, 7 y 8 OLI ofrecidas por el Servicio Geológico de los Estados Unidos (USGS). En orden procedimental se trabajó de la siguiente manera: 
1). Identificación de la zona de estudio, subregión sabana del departamento de Sucre, ingresando al USGS mediante el enlace http://glovis.usgs.gov/ para escoger de la galería, las imágenes correspondientes al Path 9 Row 54. 2). El análisis se efectúo para los últimos 32 años partiendo desde 1985, y tomando imágenes de cada 15 años en el mes de febrero. 3). Dado que el área abarcada por cada imagen es de $85 \times 85 \mathrm{~km}$, se recortaron con un shape file de la zona de estudio. 4). Se aplicó a cada una de las imágenes un realce del color para facilitar la interpretación (MIRALLES, 1991). 5). Se llevó a cabo un proceso de clasificación no supervisada según VÍLCHEZ y ENSEÑANZA (2002), cuyo fin es el reconocimiento de patrones espectrales, que de manera autónoma se convierten en igual número de coberturas (RULLÁN-SILVA et al., 2011). 6). Se elaboran los espaciomapas combinando las bandas RGB 432, la cual resalta la vegetación vigorosa de color rojo (sabanas semiantrópicas), el color rosa muestra vegetación menos densa (sabanas antrópicas), el color azul metálico resalta suelos desnudos y áreas pobladas entre otras (sabanas artificiales o praderas con o sin arbolado) (IGAC, 2005). 7). Se cuantificó el número de hectáreas por imagen y se realizó el balance.

\section{RESULTADOS Y DISCUSIÓN}

El cálculo de áreas por unidad diferenciable, teniendo en cuenta los cinco tipos utilizados en este trabajo, se muestran los cambios porcentuales por periodo se presentan en la Tabla 1. Se observa que las sabanas semiantrópicas sufrieron una disminución de $20 \%$ entre 1985 - 2001, pero luego se dio una recuperación en el mismo porcentaje en el periodo 2002-2017. Al comparar las imágenes de 1985 y 2017 , se evidencia que en estos 32 años las denominadas sabanas semiantrópicas tuvieron una recuperación equivalente a $1.025,3$ ha $(3,6 \%)$; las sabanas antrópicas se redujeron en 1.629,7 ha $(3,4 \%)$ mientras que las catalogadas como sabanas artificiales arboladas se incrementaron en 4.001,1 ha $(8,3 \%)$ y las sabanas artificiales sin arbolado en 2.270 .1 ha $(4,7 \%)$, siendo evidentemente mayor el deterioro a nivel de las sabanas artificiales, que en conjunto presentaron un aumento del área de 13,1\% (Figs. 1, 2 y 3$)$.

Tabla 1. Área por tipo de sabana y por año analizado para la zona de estudio.

\begin{tabular}{lccc}
\hline \multicolumn{1}{c}{ Formación } & $\mathbf{1 9 8 5}$ & $\mathbf{2 0 0 1}$ & $\mathbf{2 0 1 7}$ \\
\hline Sabanas semiantrópicas & $28.275,06$ & $22.583,56$ & $27.249,77$ \\
Sabanas antrópicas & $47.517,01$ & $47.791,58$ & $45.887,35$ \\
Sabanas artificiales arboladas & $48.020,13$ & $52.089,33$ & $52.021,25$ \\
Sabanas artificiales sin arbolado & $48.204,25$ & $53.135,80$ & $50.474,34$ \\
Otras & $30.700,75$ & $27.117,21$ & $27.086,36$ \\
\hline \multicolumn{1}{c}{ Total } & $\mathbf{2 0 2 . 7 1 7 , 2 1}$ & $\mathbf{2 0 2 . 7 1 7 , 5 0}$ & $\mathbf{2 0 2 . 7 1 9 , 1 0}$ \\
\hline
\end{tabular}

Tabla 2. Cambios porcentuales por periodo analizado para la zona de estudio.

\begin{tabular}{lcccc}
\hline \multirow{2}{*}{ Formación } & \multicolumn{2}{c}{ 1985 - 2001 } & \multicolumn{2}{c}{ 2002 - 2017 } \\
\cline { 2 - 5 } & $\ln \%$ & De $\%$ & $\ln \%$ & De $\%$ \\
\hline Sabanas semiantrópicas & & 20 & 20 & \\
Sabanas antrópicas & 0,6 & & & 4 \\
Sabanas artificiales arboladas & 8,4 & & & 0,12 \\
Sabanas artificiales sin arbolado & 10,2 & & & 5 \\
Otras & & 11,6 & & 0,11 \\
\hline
\end{tabular}

In: Incremento; De: Decremento

Al analizar los cambios porcentuales en función de los periodos evaluados, se puede evidenciar que las sabanas artificiales con o sin arbolado aumentaron sus áreas, lo que implicaría una degradación sucesional lenta pero persistente, que como lo señalan RORHIDI y HERRERA (1977). Se puede asumir que esta degradación es el producto de la intensidad de la intervención humana, que lleva a las sabanas antrópicas o secundarias a una transformación del paisaje por perdida de su flora y de sus ecosistemas naturales remantes, transformándolas en sabanas artificiales, cuya mayor causa negativa está representada generalmente por el pastoreo intensivo y la adecuación de potreros a través de la deforestación y quema persistente (DE LA OSSA-LACAYO et al., 2016).

Las sabanas antrópicas en general, independientemente de la estructura de su cobertura se les considera como campos productivos (GLIESSMAN et al., 1981; CHAMBERS 1983, CONWAY 1985, GLIESSMAN 1990, ALTIERI 1991; EWELL, 1999). El paisaje de sabana antrópica que caracteriza la zona de estudio, muy a pesar de la baja densidad poblacional humana, por factores de tipo productivo que datan del siglo XVI y que alcanzaron su máxima expresión en el siglo XVIII (AGUILERA-DÍAZ, 2005), están inmersos en una conversión paulatina de su cobertura herbácea en razón a la sustitución por pasturas introducidas y mejoradas de mayor productividad, proceso común en regiones similares de Brasil y Venezuela (FERREIRA y HUETE, 2004; LÓPEZ-HERNÁNDEZ et al., 2005).

Las razones que motivan la mayor proporción de cambios en las sabanas colombianas, aun cuando no están totalmente documentadas, son económicas (DE LA OSSA-LACAYO et al. (2016); se ha visto que la productividad del ganado de carne se incrementa con la introducción de pastos mejorados, por su mayor producción de biomasa. De igual modo, las explotaciones agrícolas se realizan con fines predominantemente comerciales, y la agricultura de subsistencia está relegada a huertos caseros.

Los ecosistemas de sabana, en especial los de tipo antrópico, son muy frágiles y en su mayoría están enfrentando problemas serios de degradación de los 
recursos y de viabilidad económica (SPAIN, 1992). Los factores de presión o de tensión derivados del uso, como la ocupación y transformación de ecosistemas, son los eventos que tienen mayores impactos negativos sobre la integridad del sistema, y consecuentemente conducen a una reducción de la diversidad biológica, inhibición de la capacidad de regeneración y empobrecimiento de los recursos naturales del área (WWF, 2009), aspectos que se ven traducidos en la pérdida gradual y acentuada de los elementos naturales constitutivos del ecosistema y por lo tanto se deben reflejar en cambios ecológicos y funcionales.

Los mapas que muestran las distintas coberturas por año se presentan en las Figuras. 1, 2 y 3.

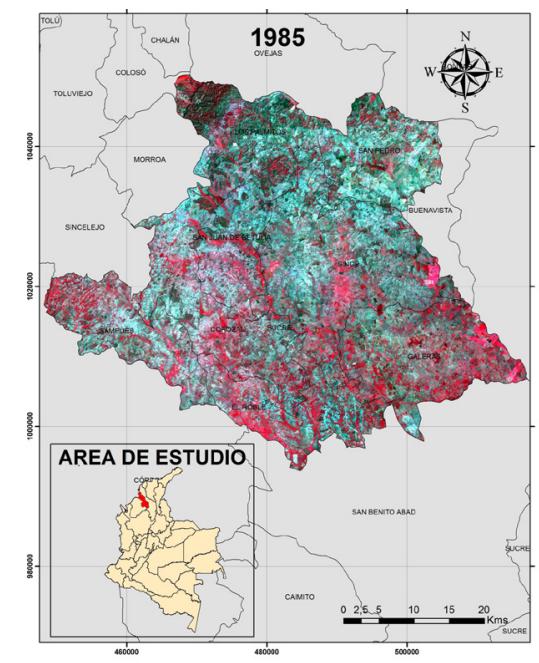

Figura 1. Cobertura de la zona estudio para el año 1985.

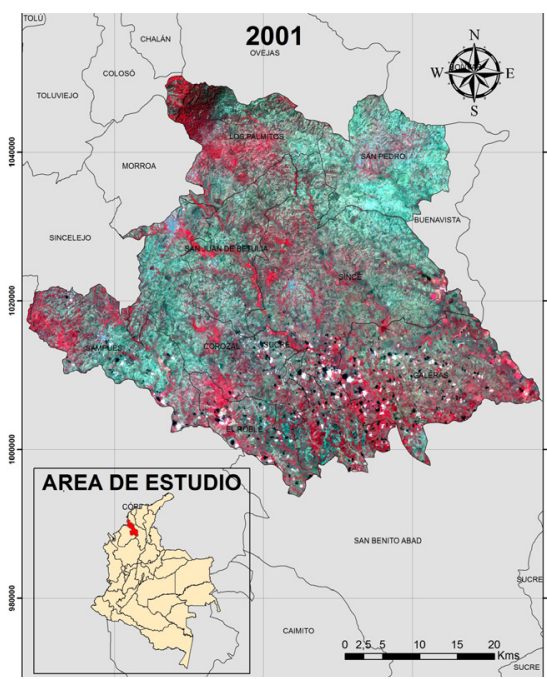

Figura 2. Cobertura de la zona estudio para el año 2001.

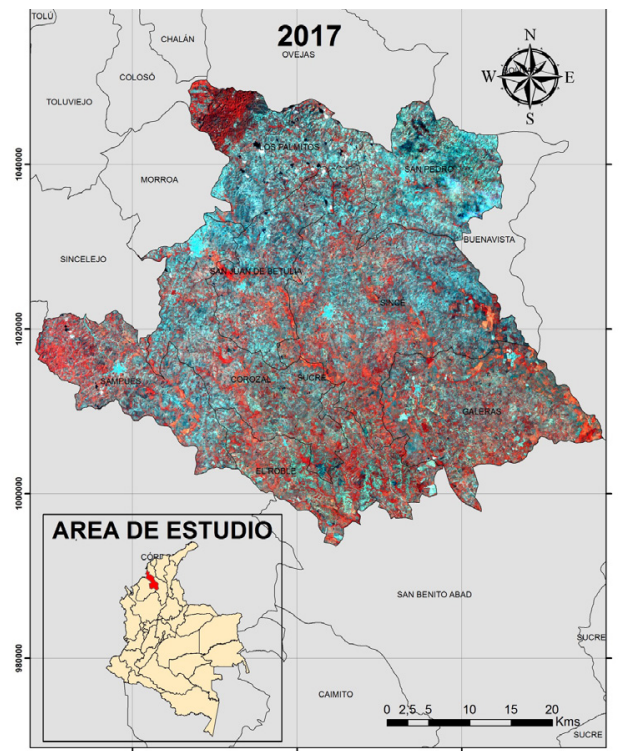

Figura 3. Cobertura de la zona estudio para el año 2017.

\section{REFERENCIAS}

AGUILERA-DÍAZ, M.M. 2005. La economía del departamento de Sucre: ganadería y sector público. Banco de la República. Documento de trabajo sobre Economía Regional Nº3. Cartagena, Colombia.

ALTIERI, M.A. 1991. Traditional farming in Latin America. The Ecologist 21(2):93-96.

CARDOSO, G.F.; SOUZA, C.; SOUZA-FILHO, P.W. 2014. Using spectral analysis of Landsat-5 TM images to map coastal wetlands in the Amazon River mouth, Brazil. Wetlands Ecology and Management 22 (1):79-92.

CHAMBERS, R. 1983. Rural development: putting the last first. Harlow, Longman. USA.

CONWAY, G. 1985. Agroecosystems analysis. Agricultural Administration 20:31-55. 
DANE. 2005. Censo general 2005. Sucre. Disponible en. http://sucre.gov.co/mapas municipio.shtml?apc=bcxx-1$\& x=1516225$. Consultada: 10-02-2017.

DE LA OSSA, V.J.; BOTERO, A.L. 2013. Vías pecuarias e importancia en la trashumancia ganadera. Rev. Colombiana cienc. Anim. 5 (1):431-438.

DE LA OSSA-LACAYO, A.; SARA TRUJILLO-V, S.; DE LA OSSA, V.J. 2016. La sabana: formación de gran valor productivo. Rev Colombiana Cienc Anim. 8(1):120-137.

EWEL, J.J. 1999. Natural systems as models for the design of sustainable systems of land use. Agroforestry Systems 45:1-21.

FERREIRA, L.G.; HUETE, A.R. 2004: Assessing the seasonal dynamics of the Brazilian Cerrado vegetation through the use of spectral vegetation indices. Int. J. Remote Sens. 25:1837-1860.

GLIESSMAN, S.R.; GARCÍA, E.R.; AMADOR, A.M. 1981. The ecological basis for the application of traditional agricultural technology in the management of tropical agro-ecosystems. Agro-Ecosystems 7:173-185.

GLIESSMAN, S.R.1990. Understanding the basis of sustainability for agriculture in the tropics: experiences in Latin America. Págs. 378-389.En: Edwards, C.A.; Lal, R.; Madden ,P. (Ed.). Sustainable agricultural systems. Ankeny, I.; O, Soil y Water Conservation Society. UK.

IGAC - INSTITUTO GEOGRÁFICO AGUSTÍN CODAZZI. 2005. Interpretación visual de imágenes de sensores remotos y su aplicación en levantamientos de cobertura y usos de la tierra. Centro de investigación y desarrollo de investigación geográfica. Bogotá, Colombia.

LÓPEZ-HERNÁNDEZ, D.; HERNÁNDEZ-HERNÁNDEZ, R.M.; BROSSARD, M. 2005. Historia del uso reciente de tierras de las sabanas de América del sur. Estudios de casos en sabanas del Orinoco. Interciencia 30: 623-630

MIRALLES, J.M. 1991. La teledetección en el seguimiento de los fenómenos naturales. Recursos Renovables: Agricultura. Universidad de Valencia. Venezuela.

RORHIDI, A.; HERRERA, R.A.1977. Génesis, características, y clasificación de los ecosistemas de sabana de Cuba. Ciencias Biológica 1:115-130.

RULLÁN-SILVA, C.D.; GAMA-CAMPILLO, L.M.; GALINDO-ALCÁNTARA, A.; OLTHOFF, A.E. 2011. Clasificación no supervisada de la cobertura de suelo de la región Sierra de Tabasco mediante imágenes. Universidad y Ciencia $27(1): 33-41$.

SALINERO, C. 2008. Teledeteccion ambiental. Editorial Ariel.

SPAIN, J.M. 1992. Sabanas neotropicales: perspectivas para sistemas integrados de producción agropecuaria, ecológica y económicamente sostenibles. Seminario Internacional Manejo Integrado de los Recursos Naturales en Ecosistemas Tropicales para una Agricultura Sostenible.Santafé de Bogotá, D.C. Colombia.

VÍLCHEZ, L.O.; ENSEÑANZA, C.A.T. DE I. 2002. Inventarios forestales para bosques latifoliados en América Central. CATIE.

VILORIA, D.J. 2005. Ganadería bovina en las llanuras del Caribe colombiano. En: Pérez, V.G.J. (Ed.). Microeconomía de la ganadería. Colección de Economía Regional, Banco de la República. Cartagena, Colombia.

WWF - World Wildlife Fund. 2009. Metodología para la evaluación y priorización rápidas del manejo de áreas protegidas. RAPPAM. 